\title{
Fan satisfaction and segmentation: A case study of minor league hockey spectators
}

Received (in revised form): 28th September, 2001

\section{Pamela A. Kennett PhD}

is an Assistant Professor in the Department of Marketing at the University of New Orleans. Her current research interests lie in the areas of sport and event marketing, particularly the determinants of fan satisfaction and evaluation of sponsorship effectiveness, and services marketing. Her work appears in journals such as the Journal of Business Research, Journal of Services Marketing and Journal of Customer Service in Marketing \& Management in addition to numerous conference proceedings.

\section{Julie Z. Sneath PhD}

is an Assistant Professor in the Business Division at LaGrange College. Her primary research interests are in consumer behaviour and sport and event marketing. A former sales manager for an international firm, her research has been published in the Journal of Shopping Center Research, Journal of Customer Service in Marketing and Management and International Sports Journal.

\section{Steve Henson PhD}

is an Associate Professor in the Department of Marketing at the University of New Orleans. His primary interests are strategic marketing and business-to-business marketing. His publications have appeared in a wide variety of marketing and business journals and proceedings.

Pamela A. Kennett PhD University of New Orleans, Department of Marketing, College of Business, New Orleans, LA 70148, USA.

Tel: +1 5042806352 ;

Fax: +1504 2805443 ;

e-mail: pkennett@uno.edu

\begin{abstract}
Given that it has been well documented that satisfied customers are important to an organisation's bottom line, steps that can be taken to increase the likelihood of having satisfied customers and retaining them should be taken. This is true across industries, but is especially critical to sports organisations. Of interest, consequently, for a sports marketer, should be how best to develop a fan satisfaction research study and based on the results of the study, how to understand satisfaction through respondent segmentation, in order to provide this necessary information and insight into the fan base. The steps involved in conducting this research are presented in an illustrative fashion by conducting an in-depth examination of this process undertaken by a minor league hockey team in the Southeastern United States.
\end{abstract}

For organisations in the multibillion dollar sports industry, spectators' level of satisfaction with the sports event experience is critical to team support, attendance at games and, ultimately, future revenues. In this maturing industry, competition for share of consumers' leisure time is intensifying. ${ }^{1}$ Subsequently, the task facing sports marketers, both now and in the future, is how to maintain interest in, and attendance at, sporting events.

Because consumers are loyal to the service providers who satisfy them, organisations must continuously assess how they might better meet or exceed consumers' expectations of and perceptions about the service experience if they are to maintain and/or grow the number of spectators and loyal fans attending sporting events. From a revenue standpoint, keeping customers 
satisfied and retaining them becomes even more critical given that, in general, it costs five times more to replace a customer than to keep a customer. ${ }^{2}$ Research also shows a strong positive relationship between customer satisfaction and performance measures such as revenues, profits and market share. ${ }^{3-5}$

It is crucial therefore for a sports marketer to understand the spectator and what drives his or her level of satisfaction. ${ }^{6,7}$ Of interest, consequently, for a sports marketer, should be how best to develop a fan satisfaction research study and based on the results of the study, how to understand satisfaction through respondent segmentation, in order to provide this necessary information and insight into the fan base. The purpose of this paper is to aid the sports marketer in accomplishing this research task by following the process undertaken by a minor league hockey team in the Southeastern United States.

\section{FAN SATISFACTION RESEARCH}

\section{Consumer evaluations of event quality}

Assessing consumers' perceptions of the service encounter, such as spectators' evaluations of their experiences at a sporting event, presents a special challenge to the sports organisation. It is more difficult for consumers to evaluate the quality of the service experience than it is to evaluate the purchase of a good. Service performance is variable and consumers may not have the skill or knowledge to assess accurately the level of quality associated with delivery of a service. In addition, measures of what constitutes 'good' service may be hard to determine, further confounding organisations' efforts to evaluate consumers' perceptions of their service offerings.

The absence of tangible cues in the services setting leads consumers to evaluate the quality of a service based on the comparison between expectations of the service prior to its performance with perceptions about the experience after the service has been performed. ${ }^{8-12}$

Research suggests, however, that some tangible cues may be present at the time of the service delivery. Furthermore, it has been shown that these elements are considered and utilised when consumers evaluate the quality of a service encounter. According to Parasuraman, Zeithaml and Berry, ${ }^{12}$ cues in the services setting may include physical facilities, equipment and personnel. For managers in the sports industry, identification of these cues and how they influence spectators' evaluations of the event experience may prove important as a tool for organisational success.

Although spectators' a priori expectations of an event may vary widely, it is likely that certain tangible factors, or cues, will be evaluated by spectators during the event itself. ${ }^{14}$ For example, while quality of team and record against opponents may be evaluated prior to an event's occurrence, other considerations such as quality of entertainment, physical facilities and interactions with employees can only be evaluated during or after the actual event. Price may also be assessed prior to an event, but price-related factors such as perceived value ('money well spent') may not be able to be evaluated until such time that the service is actually being performed or has already been performed. ${ }^{15}$ These factors, or experience qualities, are likely to be considered by fans in their assessment of the overall event experience. Because services in general, and sports events in particular, are likely to be high in experience qualities, ${ }^{16-18}$ attendees should be expected to rely upon factors such as event personnel and physical cues to 
judge the quality of their event experience. Consequently, a key managerial issue for sports marketers is to uncover those factors that are considered by consumers when they evaluate their actual experiences with the sports event.

\section{Evaluating event quality: Controllable factors}

An extensive body of research suggests that consumers' satisfaction with a service, as well as loyalty to the service provider, is influenced by the combination of a variety of factors present during the service encounter including price, convenience, employee responsiveness and other people. ${ }^{19-22}$ For example, a spectator's favourable evaluation of an event experience might be the consequence of any combination of the following factors: children had fun playing with the team mascot, desirable seat location, paying less than face value for the tickets, enjoyable conversation with a server when purchasing beer, and outcome of the game. On the other hand, this same spectator might have a negative evaluation of the event experience because of a spilled drink, pillar obstructing the view of the field, an injured player and a restroom that was out of order.

Regrettably, while some of the factors used by consumers to evaluate the sporting event experience cannot be managed or entirely controlled by the organisation, including weather conditions, team performance and injuries, many components of the event experience may be controlled or managed by the organisation, at least in part. For example, many aspects associated with a sports event, including restroom cleanliness, seating, sound system, parking, concession stands and employee courtesy, are likely to fall within the domain of controllable factors.
Sports marketers must focus on and research the factors that are fully or partially controllable and accept the fact that certain things will be beyond their control.

\section{PURPOSE OF STUDY}

A comprehensive guide to approaching a fan satisfaction survey that examines marketer-controlled factors is presented in the remainder of the paper. In essence, this study examines those variables that might be considered, and the factors that should be incorporated into a fan satisfaction study. The process utilised by a minor league hockey team in the Southeastern United States is followed in detail. These findings presented from the hockey team's research are illustrative in nature, and serve to provide an in-depth example of how to conduct, analyse and interpret results from a fan satisfaction study. By taking similar steps, it is proposed that a sports organisation can successfully replicate the procedure.

\section{CONDUCTING A FAN SATISFACTION STUDY}

\section{Overview}

There are five recommended steps to be taken to complete a fan satisfaction study that will aid in segmenting the market and developing targeted marketing programmes. First, a questionnaire needs to be developed that will cover all aspects of the fan's experience with the event. Secondly, data must be collected from a representative sample of fans. Next, fan responses must be simplified by identifying the factors that comprise satisfaction. The new factors, called determinants of satisfaction, should be examined across a wide range of potential marketing segments. Finally, the 
data must be interpreted and used to direct marketing activities. The following is a step-by-step description of the process undertaken by the researchers in conjunction with the minor league hockey team in question.

\section{Step 1: Questionnaire development}

The first step in undertaking research to better understand an organisation's fan base is to develop the survey instrument. As was done in this instance, it is recommended that the researchers work closely with management to develop the questionnaire. Specifically, the goal was to compile a list of items which were believed to contribute to customer satisfaction/dissatisfaction and which were also controllable by the sports marketer. These measures were developed using the previously shown classification of tangible cues linked to customer satisfaction with a service encounter as a basic framework. Within this framework, members of the research team and management of the hockey team independently listed all aspects of the game experience that met the outlined criteria. Past fan surveys conducted by this team and other teams were also examined by individuals when preparing their lists. Eventually, lists were combined and duplicate items eliminated. This resulted in a list of 29 separate items ranging from cost of souvenirs to music (see Appendix A for a comprehensive list).

The first part of the questionnaire asked respondents to rate their satisfaction with each of these 29 aspects of the game experience. Specifically, the fan rated his or her satisfaction using a 5 -point scale where $1=$ very satisfied and $5=$ not at all satisfied. The second part of the questionnaire asked basic demographic questions of the respondent (ie gender, age, area of residence) and behavioural questions relating to patronage of the hockey team (ie number of games attended, type of ticket holder, intent to return).

\section{Step 2: Data collection}

The second step involves collecting the data. Questionnaires were distributed to individuals attending a minor league hockey game. In this study, as individuals entered the arena, they were asked if they would be interested in participating in a fan satisfaction study. Those who were interested were given a survey. Upon completing the survey, the respondent returned it to a designated location within the arena and was given a discount coupon redeemable at the gift shop as a thank you for his or her participation. Seven hundred and eighty-six (786) questionnaires were completed and returned. To ensure a representative sample, questionnaires were distributed at various games over the course of a month making sure all days of the week and game start times were included. Given the nature of the data collection method, the exact number of fans approached and questionnaires handed out to fans is unknown. It is estimated, however, that approximately 1,200 questionnaires were distributed during the course of the research resulting in roughly 65 per cent of the distributed questionnaires being returned.

\section{Step 3: Data reduction}

Once the data have been collected and prepared for analysis, the underlying structure of the data should be examined. This is ordinarily accomplished by factor analysis, a technique whose primary purpose is data reduction and summarisation. Specifically factor analysis 'addresses the problem of analyzing the interrelationships among a large number 
Table 1: Summary of resulting factors

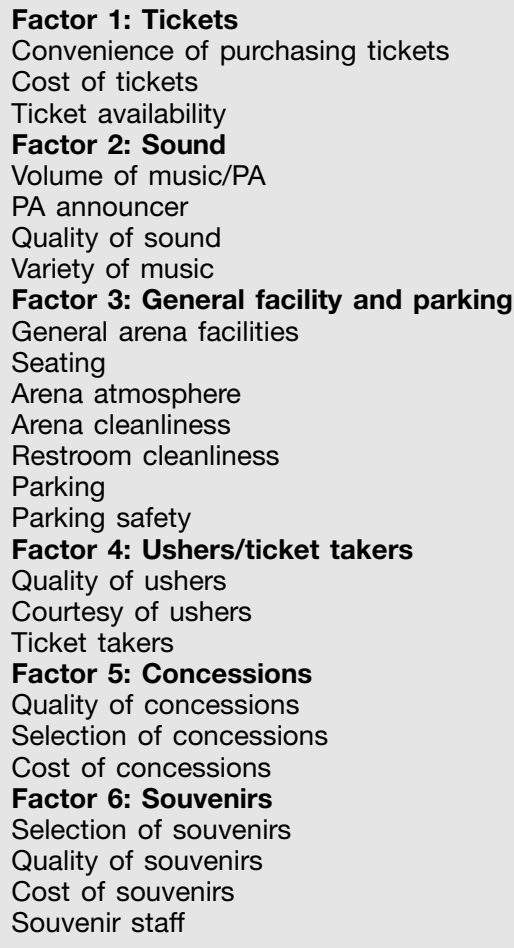

of variables and then explaining these variables in terms of their common underlying dimensions'. ${ }^{23}$ Factor analysis generally requires a statistical package, such as SPSS or SAS. Both are available in PC format and are relatively user friendly. Terminology in the rest of this section refers to commands used in SPSS 9.0 for Windows.

The 29 scale items used in the current study were subjected to a factor analysis with Varimax rotation to simplify the data. The complete results of the factor analysis are found in Appendix A. Generally speaking, a researcher seeks items that load highly on only a single factor. In this case, it was decided to use only items that loaded at least 0.63 on one of the factors and did not load higher than a 0.5 on any other factor. Five items were deleted due to low item-factor correlations. The remaining 24 items, however, produce six clean factors. Each factor deals with fan satisfaction with a certain aspect of the stadium experience. Specifically, the factors comprise satisfaction with the following: tickets, sound, general facility and parking, ushers, concessions, and souvenirs. Table 1 summarises the items contained in each of these six factors. Lastly, a test for reliability was conducted. These internal reliability tests showed strong Cronbach alphas ranging from 0.6449 to 0.8673 .

\section{Step 4: Compute factor scores and validate determinants of satisfaction}

Next, factor scores were created by averaging the items for each of the six factors. These factor scores were then correlated with overall satisfaction. These correlations are shown in Table 2. Each factor is significantly and positively related to overall satisfaction. The correlation coefficients range from a low of 0.196 (concessions) to a high of 0.342 (general facility and parking). Therefore, as a fan's satisfaction with any factor increased, so did that fan's overall satisfaction.

\section{Step 5: Segmentation of data}

To gain more insight into fan satisfaction, data can be further segmented by variables of interest. Researchers often use segmentation to provide a richer understanding of the target market being studied. ${ }^{24-26}$ For this particular study, variables representing usage (number of games attended), type of ticket purchase and behavioural intent were chosen as means of segmentation since both management and the researchers believed it likely that differences may occur across various segments within each of these variables. A summary of the segmentation results can be found in Table 3 .

First, the respondents were segmented 
Fan satisfaction and segmentation: A case study of minor league hockey spectators

Table 2: Correlation of component scores with overall satisfaction

\begin{tabular}{llc}
\hline & & Overall satisfaction \\
\hline \multirow{2}{*}{ Sound } & Pearson Correlation & 0.219 \\
& Sig. (2-tailed) & 0.000 \\
Concessions & Pearson Correlation & 771 \\
& Sig. (2-tailed) & 0.196 \\
Ushers & Pearson Correlation & 0.000 \\
& Sig. (2-tailed) & 770 \\
Tickets & Pearson Correlation & 0.272 \\
& Sig. (2-tailed) & 0.000 \\
Souvenirs & Pearson Correlation & 774 \\
& Sig. (2-tailed) & 0.228 \\
General facility/parking & Pearson Correlation & 0.000 \\
& Sig. (2-tailed) & 775 \\
& $N$ & 0.238 \\
& & 0.000 \\
& & 765 \\
& & 0.342 \\
& & 0.000 \\
\hline
\end{tabular}

Table 3: Examining market segments

\begin{tabular}{lll}
\hline Customer segments & Change & Associated with \\
\hline Level of attendance & Increased attendance & Overall satisfaction \\
& & Satisfaction with ushers \\
& & Satisfaction with souvenirs \\
Type ticket & Increased commitment & Satisfaction with facility \\
& & Satisfaction with sound \\
Likelihood to attend in future & & Satisfaction with ushers \\
& Increased likelihood & Satisfaction with tickets \\
& & Satisfaction with souvenirs \\
& & Overall satisfaction \\
& & Satisfaction with ushers \\
& & Satisfaction with tickets \\
& & Satisfaction with souvenirs \\
\hline
\end{tabular}

by the number of games attended during the season to represent different usage categories. A univariate analysis of variance (ANOVA) was conducted where usage served as the grouping variable and overall satisfaction and the six component scores served as the dependent variables. This analysis determines if differences in satisfaction exist across different levels of usage.

Several significant differences were uncovered. Differences in overall satisfaction were exhibited by different categories of users $(\mathrm{p}=0.009)$. As attendance increased, so did overall satisfaction. A similar finding is seen when examining satisfaction with usher-related issues $(\mathrm{p}=0.000)$, souvenir issues $(\mathrm{p} .=0.000)$, and general facility and parking issues $(\mathrm{p}=0.024)$. The more times a person attends during the season, the more satisfied he or she is with these three components of satisfaction. No significant differences were found when examining the other three components of satisfaction (tickets, sound and concessions).

Another method of segmentation was employed whereby respondents were categorised based on the type of ticket 
purchaser they are: a full season ticket holder, a mini-package holder or a single game ticket purchaser. Once again, a univariate analysis of variance was conducted to determine if differences in satisfaction exist across different types of purchasers. No significant differences were uncovered when it came to overall satisfaction. Each type of purchaser exhibited a similar level of overall satisfaction.

Significant differences were found, however, when it came to sound issues $(p=0.017)$, usher issues $(p=0.001)$, ticket issues $(p=0.001)$, and souvenir issues $(p=0.021)$. When it came to satisfaction with the ushers and souvenirs, the more committed the consumer (ie a full season ticket holder), the more satisfied the consumer. Conversely, when it came to sound satisfaction, the less committed the consumer, the more satisfied. Finally, another pattern emerged with respect to ticket satisfaction. The highest level of satisfaction was found among the middle level of commitment (ie the mini-package holder) followed by the full season ticket holder and then the single ticket buyer.

A final means of segmenting the data involved grouping respondents based on their behavioural intentions with respect to future games. A similar univariate analysis of variance was conducted. Not surprisingly, differences in overall satisfaction were found $(\mathrm{p}=0.000)$. Those who were likely to attend the most games in the future were the more satisfied respondents. Similar findings were found when it came to satisfaction with ushers $(p=0.000)$, tickets $(p=0.000)$, and souvenirs $(p=0.000)$. Those who indicated an intention to attend the most games in the future exhibited a higher level of satisfaction with these three components. No significant differences were found when examining the remaining three components (sound, general facility and parking and concessions).

\section{INTERPRETING A FAN SATISFACTION STUDY}

When focusing on the results of this particular study, the managers of the minor league hockey team could choose to examine levels of overall satisfaction and satisfaction for each of the 29 scale items. Where are they receiving high satisfaction ratings and where are they receiving low satisfaction ratings? If these contributors to satisfaction are controllable, adjustments, such as improvements in restroom cleanliness and employee training, could then be made wherever appropriate. Further, if this study were to be re-administered during the course of the season or from season to season, these satisfaction scores might serve as benchmarks to mark changes in satisfaction.

Less cumbersome, however, is to consider the results of the factor analysis which reduce the 29 scale items to six areas of concern for this particular sports organisation. The results show that each of these six factors is correlated with overall satisfaction. By increasing satisfaction in any of these factors, overall satisfaction should also show an increase. As previously mentioned, these factor scores can also serve as benchmarks. Those components that exhibit the highest level of correlation with overall satisfaction deserve the most attention.

In the current study, a questionnaire was developed by the researchers, with input provided by team management. Data were collected during multiple games (various days and times of day to ensure a representative sample), then analysed. Results from the first four steps of the study suggest that this organisation's resources might best be directed toward increasing fans' level of 
satisfaction with the tickets, sound, general facility and parking, ushers, concessions and souvenirs. Since the factors can be influenced or controlled by the organisation, a strategy designed to increase fan satisfaction can then be developed and appropriate steps taken.

For this particular minor league hockey team, management was encouraged to consider each factor individually and develop strategies to increase related satisfaction. For instance, when considering factor 1 (tickets), box office hours were re-evaluated to enhance the convenience of purchasing tickets. Further, while actual ticket prices were not decreased, a marketing campaign emphasising the value of the ticket when compared to other entertainment options was undertaken. Consideration of factor 2 (sound) spurred further research into the type of music that the fans wanted to hear to ensure proper variety. Factor 3 (general facility and parking) resulted in enhanced attention being placed on cleanliness. It was observed that satisfaction with cleanliness issues was an area ripe for improvement. The importance of the quality and courtesy of the ushers was apparent upon examination of factor 4 . As a result, more care was placed on the hiring and training of ushers given their frontline roles in the organisation. Lastly, the cost and variety of concessions (factor 5) and souvenirs (factor 6) were re-evaluated as a result of this research. Fans were unhappy with the price and selection in both areas and changes were made accordingly.

Perhaps the most interesting and insightful results in this study were found when respondents were segmented. Data showed that as attendance increased for this hockey team, so did overall fan satisfaction. The greater the number of games a fan attended, the greater his or her level of satisfaction with the event experience. Since fans that are not satisfied may not be returning for future games, management should focus on what can be done to increase satisfaction early in the season and for first-time game attendees. The organisation might also develop plans designed to maintain satisfaction later in the season among those who frequently attend games. For example, a team may consider developing a fan reward programme (similar to a frequent flyer programme) whereby fans earn points, redeemable in the gift shop, at the concession stand, or the ticket office, for each game attended. Also, variety in promotions and stadium entertainment is encouraged to ensure a slightly different, but consistently entertaining, experience at each trip to the ballpark.

Additionally, this fan satisfaction study showed that differences also occurred when respondents were segmented by type of ticket purchaser. Once again, the more committed consumer was more satisfied with the ushers and souvenirs. Strategies such as those previously mentioned could be implemented to increase the satisfaction of those fans that have not committed to season tickets or other ticket packages. Interestingly, those fans who are the most committed were the least satisfied when it came to sound satisfaction. Perhaps, for this team, fans who attend multiple games find the sound monotonous and lacking in variety. Since the organisation in question utilises a public announcement (pa) script for all of its games, variety, as previously mentioned, might help increase spectators' level of satisfaction with this component. Finally, different results emerged when it came to ticket satisfaction. Those fans who purchased the mini-package were the most satisfied with this aspect of the game experience. Season ticket holders were less satisfied as were single game ticket purchasers. The former might get tired of their seats since 
they sit in the same location for a large number of games while the latter probably end up with poorer seat selection. A marketing campaign that emphasises that there is not a bad seat in the house might be in order. Or, if certain segments of the market exhibit a preference for variety in their seats, then an approach that guarantees variety might be in order.

Lastly, differences in satisfaction were found when segmenting fans by behavioural intentions. Those fans who indicated the highest likelihood to return exhibited the highest level of overall satisfaction. This underscores the importance of increasing satisfaction among all groups of consumers given this relationship between satisfaction and intention to return. These same fans who were likely to return also indicated a higher level of satisfaction with ushers, tickets and souvenirs. Perhaps special attention should be devoted to these components of satisfaction since this is where the significant differences appear.

\section{MANAGERIAL IMPLICATIONS}

The motivation for conducting a fan satisfaction study is multifaceted. First, it gives a sports team feedback when it comes to the satisfaction of its customers. Secondly, it allows the team to understand how satisfaction with various components of the fan experience relates to overall satisfaction. Lastly, satisfaction can be examined further by segmenting fans using certain behavioural and behavioural intention criteria.

The most important lesson to be taken from this fan satisfaction survey is the steps to follow to replicate this for another sports organisation. Measures should be customised for each organisation using the procedure outlined in the questionnaire development section. Involvement of all members of not only the research team, but the management of the sports organisation, is critical at this point. Also, examination of other fan satisfaction surveys proves useful in generating questionnaire items. Once the questionnaire has been completed, data collection can be undertaken. It is the experience of these researchers that on-site distribution of questionnaires is most effective. Offering the fans a small, but valuable, incentive has also proved useful in the data collection process. Some sports organisations choose to supplement on-site distribution of questionnaires with other forms of data collection such as mailing out the survey in hopes of reaching fans who may not be inclined to interrupt their stadium experience to fill out a questionnaire.

Once data collection has been completed, three steps are recommended when analysing the results of a fan satisfaction study. First, factor analysis should be employed to reduce data. Secondly, the relationship between these factors and overall satisfaction should be assessed. Finally, segmentation of the data by appropriate variables should be undertaken and differences between various groups of consumers examined.

It is imperative that the sports organisation carefully considers the findings of its fan satisfaction survey and takes them to heart. Much valuable information can be gleaned from this research whether examining the results cross-sectionally (ie satisfaction at any one moment) or from a longitudinal perspective (ie changes in satisfaction over time). Given that satisfied customers are important to an organisation's bottom line, steps that can be taken to increase the likelihood of having satisfied customers and retaining them should be taken. A sports organisation must realise that not all contributors to a fan's satisfaction are controllable (eg win/loss record), but should instead identify those 
contributors that are controllable and focus its attention on these.

Lastly, the sports organisation should consider expanding the scope of its research agenda to include a second study that focuses on identifying and understanding individuals who do not attend the team's sporting events. Perhaps, by researching these non-fans, the organisation can gain insight into how to convert these individuals into long-term, satisfied customers.

\section{References}

1 Hyman, M. (1998) 'How to lose fans and get richer', Business Week, p. 70, 26th January.

2 Best, R. J. (2000) 'Market-based management', Prentice Hall, Upper Saddle River, NJ.

3 Bernhardt, K. L., Donthu, N. and Kennett, P. A. (2000) 'A longitudinal analysis of satisfaction and profitability', Journal of Business Research, Vol. 47, No. 2, pp. 161-171.

4 Anderson, E. W., Fornell, C. and Lehman, D. R. (1994) 'Customer satisfaction, market share, and profitability: Findings from Sweden', Journal of Marketing, Vol. 58, p. 53-66, July.

5 Rust, R. T. and Zahorik, A. J. (1993) 'Customer satisfaction, customer retention, and market share', Journal of Retailing, Vol. 69, pp. 193-215, Summer.

6 Robertson, D. and Pope, N. (1999) 'Product bundling and causes of attendance and non-attendance in live professional sport: A case study of the Brisbane Broncos and Brisbane Lions', Cyber-Journal of Sport Marketing, Vol. 3, No. 1.

7 Shilbury, D. (1994) 'Delivering quality service in professional sport', Sport Marketing Quarterly, Vol. 3, No. 1.

8 Gronroos, C. (1982) 'Strategic management and marketing in the service sector', Swedish School of Economics and Business Administration, Helsingfors.

9 Lehtinen, U. and Lehtinen, J. R. (1982) 'Service quality: A study of quality dimensions', unpublished manuscript, Service Management Institute, Finland, Helsinki.

10 Lewis, R. C. and Booms, B. H. (1983) 'The marketing aspects of service quality. Emerging perspectives on services marketing', Berry, L.,
Shostack, G. and Upah, G. (eds), American Marketing, pp. 99-107, Chicago.

11 Sasser, W. E., Jr., Olsen, R. P. and Wyckoff, D. D. (1978) 'Management of service operations: Text and cases', Allyn and Bacon, Boston.

12 Parasuraman, A., Zeithaml, V. A. and Berry, L. (1985) 'A conceptual model of service quality and its implications for future research', Journal of Marketing, Vol. 49, pp. 41-50, Fall.

13 Ibid.

14 Nelson, P. (1972) 'Advertising as information', Journal of Political Economy, Vol. 81, pp. 729-754, July/August.

15 Zeithaml, V. A. and Bitner, M. J. (2000) 'Services marketing, McGraw Hill, Boston.

16 Nelson (1972) op. cit.

17 Darby, M. R. and Karni, E. (1973) 'Free competition and the optimal amount of fraud', Journal of Law and Economics, Vol. 16, pp. 67-86, April.

18 Ostrom, A. and Iacobucci, D. (1995) 'Consumer trade-offs and the evaluation of services', Journal of Marketing, pp. 17-28, January.

19 Keaveney, S. M. (1995) 'Customer switching behaviors in services industries: An exploratory study', Journal of Marketing, pp. 71-82, April.

20 Mohr, L. A., Bitner, M. J. and Booms, B. H. (1994) 'Critical service encounters: The employee's viewpoint', Journal of Marketing, pp. 95-106, October.

21 Price, L. L., Arnould, E. J. and Tierney, P. (1995) 'Going to extremes: Managing service encounters and assessing provider performance', Journal of Marketing, pp. 83-97, April.

22 Hartline, M. D. and Ferrell, O. C. (1996) 'The management of customer-contact service employees: An empirical investigation', Journal of Marketing, pp. 52-70, October.

23 Hair, J. F., Anderson, R. E., Tatham, R. L. and Black, W. C. (1992) 'Multivariate data analysis with readings', Macmillan Publishing Company, New York.

24 Swanson, L. A. (1998) 'Market segmentation in the People's Republic of China', Journal of Segmentation in Marketing, Vol. 2, pp. 99-116.

25 Swinyard, W. R. (1998) 'Spiritual solace on two wheels: The motorcycle mystique and rider segments', Journal of Segmentation in Marketing, Vol. 2, pp. 7-25.

26 Morritt, R. (1997) 'Niche marketing for hotel managers', Journal of Segmentation in Marketing, Vol. 2, pp. 103-119. 
Appendix A: Factor analysis of components of fan satisfaction

\begin{tabular}{|c|c|c|c|c|c|c|}
\hline & $\begin{array}{l}\text { General } \\
\text { facility } \\
\text { and } \\
\text { parking }\end{array}$ & Sound & Souvenirs & $\begin{array}{l}\text { Ushers/ } \\
\text { ticket } \\
\text { takers }\end{array}$ & Concessions & Tickets \\
\hline Convenience of purchasing & 0.126 & 0.023 & 0.033 & 0.145 & 0.058 & 0.664 \\
\hline Cost of tickets & 0.085 & 0.217 & 0.198 & 0.044 & 0.162 & 0.690 \\
\hline Ticket availability & 0.111 & 0.198 & 0.120 & 0.104 & 0.041 & 0.767 \\
\hline Game promos* & 0.225 & 0.521 & 0.049 & 0.042 & 0.278 & 0.308 \\
\hline Mascot* & 0.154 & 0.498 & 0.142 & 0.206 & 0.112 & 0.255 \\
\hline Volume of music/PA & 0.039 & 0.727 & 0.049 & 0.061 & 0.065 & -0.007 \\
\hline PA announcer & 0.173 & 0.721 & 0.068 & 0.098 & 0.039 & 0.022 \\
\hline Quality of sound & 0.137 & 0.710 & 0.106 & -0.052 & -0.007 & 0.211 \\
\hline Variety of music & 0.131 & 0.712 & 0.129 & 0.097 & 0.078 & 0.018 \\
\hline Team management and staff* & 0.182 & 0.514 & 0.154 & 0.216 & 0.043 & 0.411 \\
\hline General arena facilities & 0.739 & 0.274 & 0.069 & 0.197 & 0.138 & 0.029 \\
\hline Seating & 0.672 & 0.182 & -0.025 & 0.218 & 0.138 & -0.003 \\
\hline Arena atmosphere & 0.680 & 0.330 & 0.093 & 0.185 & 0.199 & 0.112 \\
\hline Arena cleanliness & 0.653 & 0.100 & 0.107 & 0.088 & 0.202 & 0.037 \\
\hline Restroom cleanliness & 0.659 & 0.117 & 0.132 & 0.118 & 0.312 & 0.069 \\
\hline Parking & 0.730 & 0.034 & 0.312 & 0.108 & 0.042 & 0.341 \\
\hline Parking safety & 0.720 & 0.054 & 0.311 & 0.092 & -0.013 & 0.290 \\
\hline Stadium security* & 0.349 & 0.099 & 0.174 & 0.284 & -0.178 & 0.115 \\
\hline Quality of ushers & 0.401 & 0.157 & 0.213 & 0.681 & 0.048 & 0.146 \\
\hline Courtesy of ushers & 0.131 & 0.099 & 0.078 & 0.737 & 0.096 & 0.022 \\
\hline Ticket takers & 0.213 & 0.057 & 0.145 & 0.631 & 0.071 & 0.222 \\
\hline Quality of concessions & 0.293 & 0.155 & 0.119 & 0.186 & 0.782 & 0.142 \\
\hline Selection of concessions & 0.257 & 0.143 & 0.149 & 0.181 & 0.807 & 0.110 \\
\hline Cost of concessions & 0.096 & 0.051 & 0.364 & -0.061 & 0.670 & 0.062 \\
\hline Concession employees* & 0.148 & 0.119 & 0.398 & 0.492 & 0.385 & 0.099 \\
\hline Selection of souvenirs & 0.250 & 0.213 & 0.703 & 0.290 & 0.181 & 0.083 \\
\hline Quality of souvenirs & 0.196 & 0.195 & 0.786 & 0.301 & 0.142 & 0.090 \\
\hline Cost of souvenirs & 0.141 & 0.092 & 0.731 & -0.041 & 0.253 & 0.210 \\
\hline Souvenir staff & 0.186 & 0.174 & 0.599 & 0.443 & 0.128 & 0.158 \\
\hline
\end{tabular}

*Items deleted due to low item - factor correlations. 